\title{
Two-Dimensional Coordination Networks from Cyclic Dipeptides
}

Yuanyuan Guo, ${ }^{1}$ Ajiguli Nuermaimaiti, ${ }^{1}$ Niels Due Kjeldsen, ${ }^{1}$ Kurt V. Gothelf, ${ }^{1,2}$ and Trolle R. Linderoth,,${ }^{1,3^{*}}$

1 Interdisciplinary Nanoscience Center (iNANO), Aarhus University, Gustav Wieds Vej 14, 8000 Aarhus C, Denmark

2 Department of Chemistry, Aarhus University, Langelandsgade 140, 8000 Aarhus C, Denmark

3 Department of Physics and Astronomy, Aarhus University, Ny Munkegade 120, 8000 Aarhus C, Denmark

\section{Contents}

S1: Synthesis of cyclic peptides

S2: Experimental details for UHV STM and XPS measurements

S3: Synthesis of Cyclo(L-Ala-L-Ala) coordination network and calibration of peptide/Cu ratio

S4: Adsorption structure of Cyclo(L-Ala-D-Ala) on Au (111)

S5: Adsorption structures of Cyclo(Gly-Gly) and Cyclo(Gly-Gly)-Cu on Au (111)

References

*E-mail: trolle@inano.au.dk 
S1: Synthesis of cyclic peptides<smiles>CC(NC(=O)OC(C)(C)C)C(=O)O</smiles><smiles>COC(=O)C(C)N</smiles><smiles>COC(=O)[C@H](C)NC(=O)C(C)NC(=O)OC(C)(C)C</smiles><smiles>C[C@@H]1NC(=O)[C@@H](C)NC1=O</smiles><smiles>CC(NC(=O)OC(C)(C)C)C(=O)O</smiles><smiles>COC(=O)C(C)N</smiles><smiles>COC(=O)[C@H](C)NC(=O)C(C)NC(=O)OC(C)(C)C</smiles><smiles>CC1NC(=O)[C@H](C)NC1=O</smiles>

Scheme S1 Synthesis of diketopiperazine analogs.

Cyclo(G-G) (2,5-piperazinedione) (> 98\%) was purchased from Sigma-Aldrich Co., Ltd.

Cyclo-( $L$-Ala- $L$-Ala) was synthesized by first coupling $N$-Boc- $L$-Ala with $L$-Ala-OMe followed by acidic deprotection and then cyclization in a refluxing mixture of sec-butanol and toluene.

Analogously cyclo( $L$-Ala- $D$-Ala) was synthesized by coupling N-Boc- $L$-Ala with $D$-Ala-OMe according to a literature procedure, ${ }^{1}$ followed by acidic deprotection and then cyclization in a refluxing mixture of Sec-butanol and toluene. The experimental details are described in the following paragraphs.

Solvents for reactions were of HPLC or technical grade purity. Reactions were monitored with TLC using Merck ${ }^{\circledast}$ silica gel $60 \mathrm{~F}_{254}$ TLC plates. Bands on TLC plates were visualized under UV-light or by staining with $\mathrm{KMnO}_{4}$, anisaldehyde, phosphomolybdic acid or cerium ammonium molybdate stains. Reagents were purchased from Sigma-Aldrich, Apollo Scientific or TCI chemicals. Commercially available reagents were used without purification.

\section{S1-1.Boc-(L-Ala-L-Ala)-OMe}<smiles>COC(=O)[C@H](C)NC(=O)[C@H](C)NC(=O)OCc1ccccc1</smiles>

To a Schlenk flask was added Boc- $L$-Ala-OH $(1.00 \mathrm{~g}, 5.3 \mathrm{mmol})$ and $L$-Ala-OMe $(737 \mathrm{mg}, 5.3 \mathrm{mmol})$. The solids were suspended in DCM $(16 \mathrm{~mL})$ and cooled with an ice/water bath. To the mixture was added HBTU $(2.10 \mathrm{~g}, 5.55 \mathrm{mmol})$ followed by DIPEA $(2.77 \mathrm{~mL}, 15.86 \mathrm{mmol})$ in small portions during $10 \mathrm{~min}$. The mixture was stirred for $15 \mathrm{~min}$ at this temperature and the cooling bath was removed. The mixture was stirred at $\mathrm{rt}$ overnight at which point TLC indicated near full conversion of the acid. The mixture was concentrated in vacuo and the residue suspended in EtOAc $(50 \mathrm{~mL})$. The solution was sequentially washed with water $(3 \times 30 \mathrm{~mL})$, sat. aq. $\mathrm{NaHCO}_{3}(3 \times 30 \mathrm{~mL})$ and $0.6 \mathrm{M}$ hydrochloric acid $(3 \times 30 \mathrm{~mL})$. The organic layer was dried over $\mathrm{MgSO}_{4}$ and concentrated in vacuo. This gave the title compound as an opaque, semicrystalline solid ( $973 \mathrm{mg}, 3.55 \mathrm{mmol}, 67 \%$ ). The spectroscopic data matched the previously reported. ${ }^{2}$ 


\section{S1-2. (3S, 6S)-3,6-Dimethylpiperazine-2,5-dione (Cyclo(L-Ala-L-Ala))}<smiles>C[C@@H]1NC(=O)[C@@H](C)NC1=O</smiles>

A solution of Boc-L-Ala- L-Ala-OMe (400 mg, $1.46 \mathrm{mmol})$ in $\mathrm{HCOOH}(30 \mathrm{~mL})$ and stirred for $2 \mathrm{~h}$ at $\mathrm{rt}$. At this point TLC indicated full conversion of the starting material. The solvent was removed in vacuo and the residue suspended in $s \mathrm{BuOH}(15 \mathrm{~mL})$ and $\mathrm{PhMe}(10 \mathrm{~mL})$. The mixture was refluxed overnight at $120^{\circ} \mathrm{C}$ overnight and cooled to rt. The solvent was removed in vacuo and the crude product was purified by recrystallization from $\mathrm{MeOH}$. This provided the title product as colorless crystals $(153 \mathrm{mg}, 1.08 \mathrm{mmol}, 74 \%)$. The spectroscopic data matched the previously reported. ${ }^{3}$

\section{S1-3.Meso-3,6-Dimethylpiperazine-2,5-dione (Cyclo(L-Ala-D-Ala))}<smiles>C[C@@H]1NC(=O)[C@@H](C)NC1=O</smiles>

A solution of Boc- $L-A l a-D-A l a-O M e^{1}(300 \mathrm{mg}, 1.09 \mathrm{mmol})$ in $\mathrm{HCOOH}(30 \mathrm{~mL})$ and stirred for $2 \mathrm{~h}$ at $\mathrm{rt}$. At this point TLC indicated full conversion of the starting material. The solvent was removed in vacuo and the residue suspended in $s \mathrm{BuOH}(15 \mathrm{~mL})$ and $\mathrm{PhMe}(10 \mathrm{~mL})$. The mixture was refluxed overnight at $120^{\circ} \mathrm{C}$ overnight and cooled to rt. The solvent was removed in vacuo and the crude product was purified by recrystallization from $\mathrm{MeOH}$. This provided the title product as colorless crystals ( $129 \mathrm{mg}, 0.91 \mathrm{mmol}, 83 \%)$. The spectroscopic data matched the previously reported. ${ }^{4}$

\section{S2: Experimental details for UHV STM and XPS measurements}

The experiments were performed in two UHV chambers, both equipped with an "Aarhus"-type STM and one in addition with a SPECS Phoibos 150 electron energy analyzer and a SPECS XR $50 \mathrm{x}$-ray source for X-ray Photoelectron spectroscopy (XPS). For the XPS measurements Al Ka radiation (1486.6 eV) was used and binding energies were calibrated against the $\mathrm{Au} 4 \mathrm{f} 7 / 2$ peak located at $84.0 \mathrm{eV} .^{5}$ The $\mathrm{Au}(111)$ single crystal surface was prepared by repeated cycles of Ar+ sputtering and subsequent annealing. ${ }^{6}$ The quality and cleanliness of the substrate surface was assessed by STM and XPS. Cyclo(L-Ala-L-Ala), Cyclo(L-Ala-D-Ala) and Cyclo(Gly-Gly) molecules were deposited in-situ from separate glass crucibles heated to $340 \mathrm{~K}, 340 \mathrm{~K}$ and $373 \mathrm{~K}$ respectively onto a $\mathrm{Au}(111)$ substrate held at room temperature (RT). $\mathrm{Cu}$ atoms were dosed from a droplet of melted $\mathrm{Cu}$ held in a resistively heated $\mathrm{W}$-basket. The sample was transferred within the UHV chamber to the scanning tunneling microscope or the XPS sample holder for measurement at temperatures down to $100 \mathrm{~K}$. Experiments were repeated independently more than ten times showing the coordination network to form in a highly reproducible fashion on two different $\mathrm{Au}$ (111) surfaces and in two different vacuum chambers. 


\section{S3: Synthesis of Cyclo-(L-Ala-L-Ala) coordination network and calibration of peptide/Cu ratio.}

The Cyclo-(L-Ala-L-Ala)-Cu coordination network of Figs $1 \mathrm{~d}$ and $2 \mathrm{~d}$ were formed after adding $\mathrm{Cu}$ adatoms to a surface with adsorbed Cyclo-(L-Ala-L-Ala) molecules. Because the individual metal atom centers in the surface coordination network were not resolved by STM (as is often the case in surface coordination networks ${ }^{7-9}$ ) we followed the procedure described below to establish the molecule-metal ratio in the network. Coverages of peptides and $\mathrm{Cu}$ atoms are given in ML where $1 \mathrm{ML}$ corresponds to one adsorbate atom or molecule per Au (111) unit cell.

The $\mathrm{Cu}$ deposition rate was calibrated from experiments where $\mathrm{Cu}$ islands were grown on clean $\mathrm{Au}(111)$ as shown in the STM image of Fig S1. Here $\mathrm{Cu}$ atoms were dosed onto the $\mathrm{Au}(111)$ surface for 30 minutes at a substrate temperature of $185 \mathrm{~K}-200 \mathrm{~K}$ to promote island formation and prevent alloying of $\mathrm{Cu}$ atoms into the bulk crystal. The surface coverage of the monoatomically high $\mathrm{Cu}$ islands was calculated by STM image analysis software. The coverage of $\mathrm{Cu}$ atoms was found to be $0.3 \mathrm{ML}$ corresponding to a $\mathrm{Cu}$ deposition rate of $0.01 \mathrm{ML} / \mathrm{min}$.

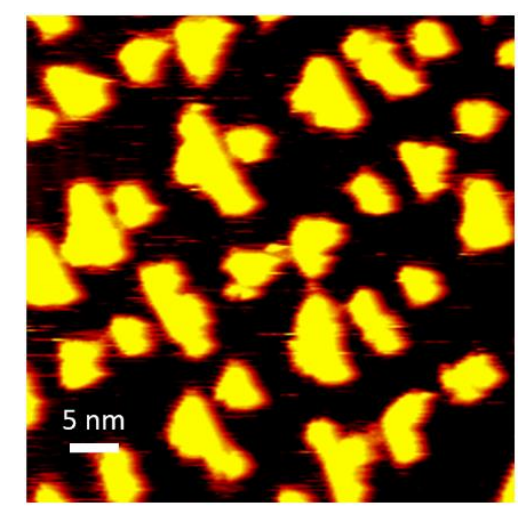

Figure S1. Cu islands on $\mathrm{Au}(111)(\mathrm{It}=0.32 \mathrm{nA}, \mathrm{Vt}=2.02 \mathrm{~V})$.

In the experiments to form the coordination network, Cyclo-(L-Ala-L-Ala) molecules were deposited on clean Au (111) at RT, and then the Au (111) substrate was cooled down to $200 \mathrm{~K}$ with subsequent deposition of $\mathrm{Cu}$ atoms using the same evaporation rate as in the $\mathrm{Cu}$ calibration experiment. The coverage of molecules and $\mathrm{Cu}$-adatoms were optimized until the entire surface (>95\%) was covered by network structure. The coverage of Cyclo-(L-Ala-L-Ala) in the optimized network covering the entire surface was found to be $0.13 \mathrm{ML}$ from the size of the network unit cell containing three Cyclo-(L-Ala-L-Ala) molecules, as established from the STM images (Fig 1d). The corresponding Cu adatom coverage in the optimized network was determined to be $0.09 \mathrm{ML}$ from the Cudeposition time and the calibrated deposition rate (as an average over three separate network synthesis experiments). The molecule-metal ratio was thus established as $0.13 \mathrm{ML} / 0.09 \mathrm{ML}(\sim 1.4)$ or $2 \mathrm{Cu}$ adatoms per network unit cell.

It should be noted that identical coordination networks could be prepared on a Au (111) substrate held at room temperature $(300 \mathrm{~K})$ as were formed at $200 \mathrm{~K}$, and their XPS spectra were also identical, so the substrate temperature does not appear to be critical in this temperature range. 


\section{S4: Adsorption structure of Cyclo(L-Ala-D-Ala) on Au (111)}

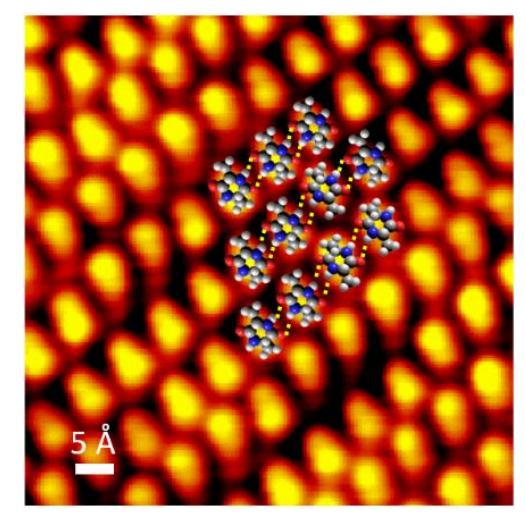

Figure S2 STM image of close-packed Cyclo(L-Ala-D-Ala) on Au (111) overlaid by corresponding ball-and-stick models (It $=-0.21 \mathrm{nA}, \mathrm{Vt}=-1.40 \mathrm{~V})$.

Cyclo(L-Ala-D-Ala) molecules self-assemble in a similar close-packed structure on Au (111) as Cyclo(L-Ala-L-Ala) molecules (see Fig S2) which is thought to involve hydrogen bonding as indicated in the overlaid model.

\section{S5: Adsorption structures of Cyclo(Gly-Gly) and Cyclo(Gly-Gly)-Cu on Au (111)}
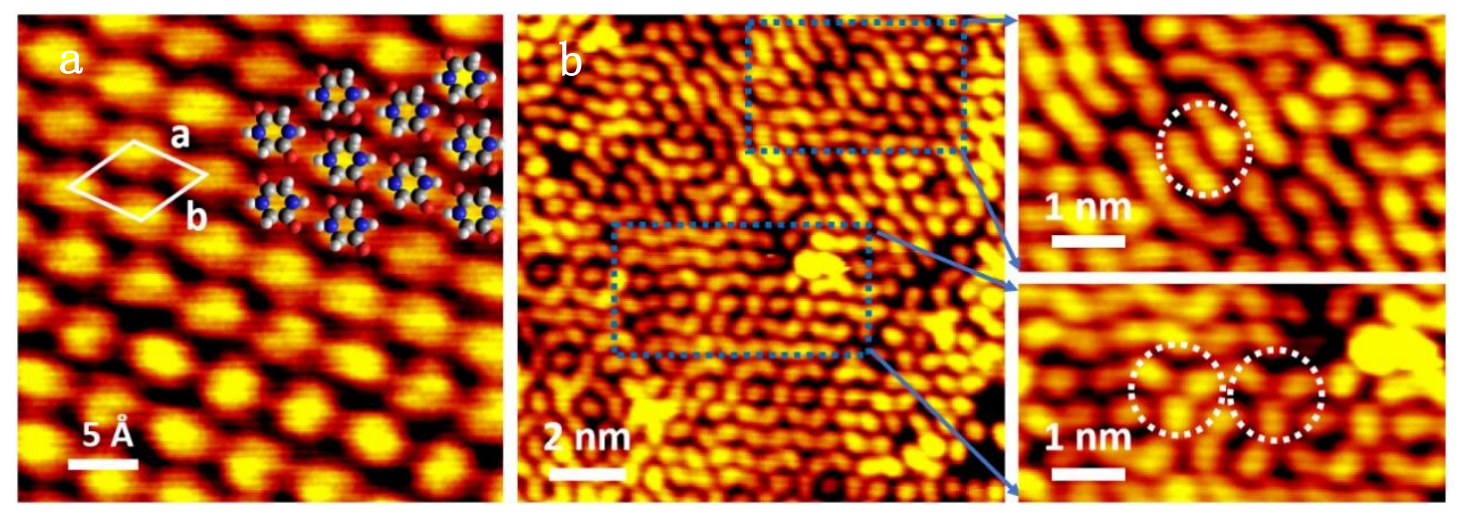

Figure S3 a) STM image of close-packed Cyclo(Gly-Gly) structure on Au (111). A unit cell is shown with dimensions a = $0.56 \pm 0.04 \mathrm{~nm}, \mathrm{~b}=0.54 \pm 0.04 \mathrm{~nm}$. $\mathrm{I}_{\mathrm{t}}=-0.21 \mathrm{nA}, \mathrm{V}_{\mathrm{t}}=-1.53 \mathrm{~V}$. Molecular models are superimposed to indicate possible interaction motifs.b) STM image of Cyclo(Gly-Gly)-Cu co-adsorption structure $\mathrm{I}_{t}=-0.34 \mathrm{nA}, \mathrm{V}_{t}=-1.53 \mathrm{~V}$. Magnified views of the areas in blue rectangles are shown in the panels to the far right; the topmost panel focuses on an irregular belt structure, while the bottommost panel shows trimer motifs with similarity to the LD-AA-Cu network.

Fig S3a shows the close-packed structure of Cyclo(Gly-Gly). The distance between neighboring molecules along the axis of the peptide backbone is $0.56 \pm 0.04 \mathrm{~nm}$ which is smaller than the distance between the Cyclo(L-Ala-L-Ala) molecules shown in Fig $1 \mathrm{~b}$. This smaller separation suggests that the side group with minimum steric effect may cause stronger hydrogen bond between the cyclic peptides. After addition of $\mathrm{Cu}$ atoms, the STM images (Fig S3b) show irregular chain structures of Cyclo(Gly-Gly)-Cu (magnified view on right top) with less porous structures (magnified view on right bottom). Dimers and trimers, which may be Cyclo(Gly-Gly)-Cu coordination units, are highlighted by white circles in the magnified view to the right. Despite several attempts, it did not prove possible to synthesize a regular coordination network from Cyclo(Gly-Gly). This result suggests that the residues of the cyclic peptides may be directly involved in the network formation, or a stronger hydrogen bonding in the Cyclo(Gly-Gly) close-packed structure, 
caused by the absence of bulky residues, inhibit the spread of molecules on the surface.

\section{REFERENCES}

(1) Behera, H.; Ramkumar, V.; Madhavan, N., Cation-Transporting Peptides: Scaffolds for Functionalized Pores. Chem. Eur. J 2015, 21, 10179-10184.

(2) Modvig, A.; Andersen, T. L.; Taaning, R. H.; Lindhardt, A. T.; Skrydstrup, T., Two-Chamber Hydrogen Generation and Application: Access to Pressurized Deuterium Gas. J. Org. Chem. 2014, 79, 5861-5868.

(3) Tanatani, A.; Mio, M. J.; Moore, J. S., Chain Length-Dependent Affinity of Helical Foldamers for a Rodlike Guest. J. Am. Chem. Soc. 2001, 123, 1792-1793.

(4) Ozaki, T. S., A., Synthesis of Cyclic Dipeptides by Use of Nps - Dipeptide Benzyl Esters as Intermediates. Makromol. Chem., Rapid Commun. 1983, 4, 363-369.

(5) Jiang, L.; Papageorgiou, A. C.; Oh, S. C.; Sag lam, O. z.; Reichert, J.; Duncan, D. A.; Zhang, Y.-Q.; Klappenberger, F.; Guo, Y.; Allegretti, F., Synthesis of Pyrene-Fused Pyrazaacenes on Metal Surfaces: Toward One-Dimensional Conjugated Nanostructures. ACS nano 2016, 10, 1033-1041.

(6) Nuermaimaiti, A.; Bombis, C.; Knudsen, M. M.; Cramer, J. R.; Lægsgaard, E.; Besenbacher, F.; Gothelf, K. V.; Linderoth, T. R., Chiral Induction with Chiral Conformational Switches in the Limit of Low "Sergeants to Soldiers" Ratio. ACS nano 2014, 8, 8074-8081.

(7) Shchyrba, A.; Wa“ckerlin, C.; Nowakowski, J.; Nowakowska, S.; Bjo“rk, J.; Fatayer, S.; Girovsky, J.; Nijs, T.; Martens, S. C.; Kleibert, A., Controlling the Dimensionality of on-Surface Coordination Polymers Via Endo-or Exoligation. J. Am. Chem. Soc. 2014, 136, 9355-9363.

(8) Sirtl, T.; Schlo“gl, S.; Rastgoo-Lahrood, A.; Jelic, J.; Neogi, S.; Schmittel, M.; Heckl, W. M.; Reuter, K.; Lackinger, M., Control of Intermolecular Bonds by Deposition Rates at Room Temperature: Hydrogen Bonds Versus Metal Coordination in Trinitrile Monolayers. J. Am. Chem. Soc. 2013, 135, 691695.

(9) Björk, J.; Matena, M.; Dyer, M. S.; Enache, M.; Lobo-Checa, J.; Gade, L. H.; Jung, T. A.; Stöhr, M.; Persson, M., Stm Fingerprint of Molecule-Adatom Interactions in a Self-Assembled Metal-Organic Surface Coordination Network on $\mathrm{Cu}$ (111). Phys. Chem. Chem. Phys. 2010, 12, 8815-8821. 